\title{
Analysis of the stress state at the double-step joint in heavy timber structures
}

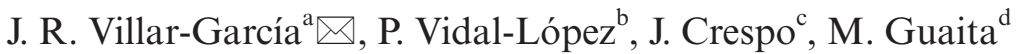 \\ a. Departamento de Ingeniería del Medio Agronómico y Forestal, Centro Universitario de Plasencia, \\ Universidad de Extremadura (Plasencia, Spain) \\ b. Grupo de Investigación Ingeniería Mecánica y Fluidos, Departamento de Ingeniería del Medio Agronómico y Forestal, \\ c. Plataforma de Ingeniería de la Madera Estructural, Escuela Politécnica Superior, Universidad de Santiago \\ de Compostela (Lugo, Spain) \\ d. Plataforma de Ingeniería de la Madera Estructural, Departamento de Ingeniería Agroforestal, Universidad de \\ Santiago de Compostela (Lugo, Spain) \\ \jrvillar@unex.es
}

\begin{abstract}
The double-step joint is among the most frequently used layouts, within carpentry joints, for transmitting higher forces that would allow a single notch. They are especially effective in heavy timber structures. Nowadays, computer-aided manufacturing is being used more often, demanding further progress in its understanding. The conventional design of these joints is conducted by using simplifying assumptions, in particular regarding the shear stress distribution. This is overcome by the use of strength reduction coefficient, which is currently under study. Numerical simulation and experimental tests were carried out with heavy timber crosssections for rafter to tie-beam truss joint. They were manufactured in glue-laminated timber owing to the large cross-sections tested. Experimental load-strain and load-displacement diagrams were compared with numerical results. This allowed observing the great shear stress concentration produced in the failure by shear crack, which suggests the application of conservative shear strength reduction coefficients.
\end{abstract}

KEYWORDS: Wood; Method of finite elements; Modelization; Mechanical properties; Deformation

Citation/Citar como: Villar-García, J.R.; Vidal-López, P.; Crespo, J.; Guaita, M. (2019) Analysis of the stress state at the double-step joint in heavy timber structures. Mater. Construcc. 69 [335], e196. https://doi.org/10.3989/ mc.2019.00319

RESUMEN: Análisis del estado tensional de la unión por embarbillado doble en estructuras pesadas de madera. Entre las uniones carpinteras, el embarbillado doble es una de las más utilizadas para transmitir cargas superiores a las que permitiría una única entalladura, especialmente interesante para estructuras pesadas. Hoy en día, la fabricación asistida por ordenador ha estimulado su uso, demandando profundizar en su estudio. El diseño convencional de estas uniones se realiza asumiendo supuestos simplificadores, en particular respecto a la distribución de las tensiones tangenciales en el cogote. Derivando en el empleo de factores de penalización de la resistencia, los cuales continúan actualmente en estudio. Se realizaron ensayos con escuadrías propias de cerchas pesadas en configuración par-tirante, empleándose para ello madera laminada. Los gráficos experimentales de carga-deformación y carga-desplazamiento se compararon con la modelización numérica de la unión. Esto permitió apreciar la importante concentración de tensiones tangenciales que se produce en el fallo por rasante, lo que aconseja la aplicación de factores reductores de resistencia a cortante conservadores.

PALABRAS CLAVE: Madera; Análisis de elementos finitos; Modelización; Propiedades mecánicas; Deformación

ORCID ID: J. R. Villar-García (https://orcid.org/0000-0003-1283-606X); P. Vidal-López (https://orcid.org/0000-00028941-604X); J. Crespo (https://orcid.org/0000-0003-1517-4030); M. Guaita (https://orcid.org/0000-0001-9159-7348)

Copyright: (C) 2019 CSIC. This is an open-access article distributed under the terms of the Creative Commons Attribution 4.0 International (CC BY 4.0) License. 


\section{INTRODUCTION}

The definition of joints characteristics for design becomes especially important, in wooden structures, as it is fundamental for the structural integrity of the buildings. Such joints can be constructed by transferring the stresses through metal fasteners or connection devices, known as mechanical joints. They can also be solved without mechanical joints, through compressions among contact surfaces and shear strains, which are the so-called traditional or carpentry joints. The anisotropic nature of wood material strongly conditions the stress transmission in carpentry joints with respect to three principal directions: i) axial direction, parallel to the grain and the tree axis, ii) radial direction, normal to the axial one and the growth rings, iii) tangential direction, normal to the axial one but tangent to the growth rings. Therefore, as for the mechanical features, wood is an orthotropic material, which affects the design and calculation of the joints.

The so-called framed joints are those whose members are linked at an angle. Within these, the so-called cogging or stepped joints are the arrangements in which the notches in the pieces allow load transmission. In this paper, the double-step, frontnotched, joint is studied. Two notches in the support beam accommodate the two steps in the upper beam (usually a rafter), as displayed in Figure 1, which is a widely used solution when the force to be transmitted is greater than those admissible for a single step joint. A perpendicular rear notch $\left(90^{\circ}\right)$ and a frontal notch in the bisectrix are usually considered to manufacture it, Figure 1.

The computer-aided manufacturing (CAM), Figure 2, has increased the used of carpentry joints as it lowered the cost and improved the accuracy of its execution. The use of these carpentry joints is rising in both, the traditional and the modern timber constructions. The reason why this trend is growing is related to the enormous influence of the joints in the cost optimisation of timber structures (1).

Although several works are studying mechanical fasterners, it is not the same for traditional or carpentry joints. The information published on stepped joints is quite limited, especially with real size test and numerical modelling together. The researches that could be mentioned here have been performed by Parisi and Piazza (2) and Villar et al. $(3,4)$ on single step joint, Villar et al. (5) on reverse step joint or the step combined with the mortise and tenon joint (6); all of them include numerical simulation. As for double step joint, only the numerical simulation carried out by Parisi and Cordie (7) can be referred, which mainly focuses on rotational stiffness, although it does not include an experimental comparison of the numerical model. Interesting experimental studies were conducted by Branco et al. (8), Palma and Cruz (9) and Palma et al. (10),

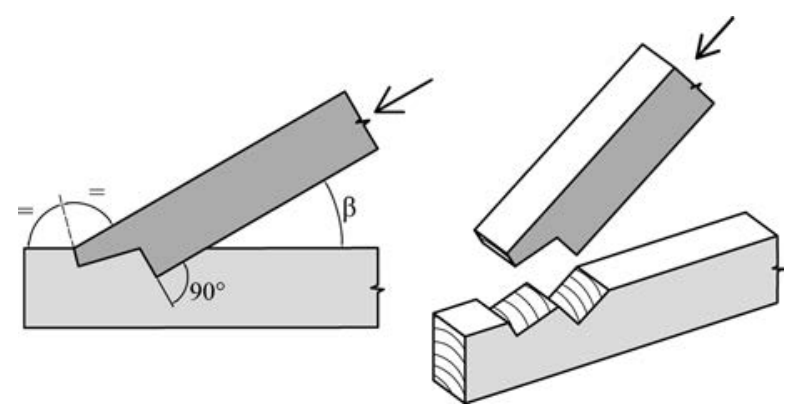

Figure 1. Double-step joint.

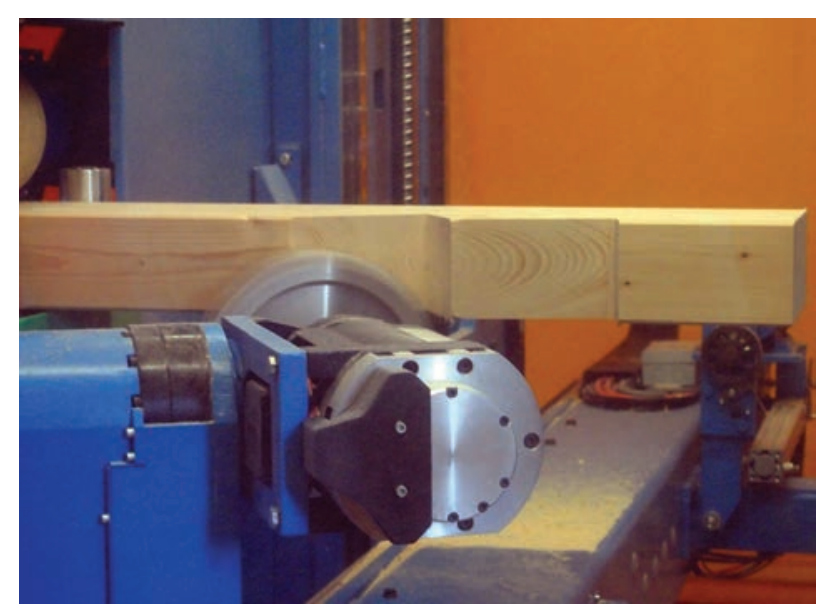

Figure 2. Computer-aided manufacturing (CAM) of notches for a double-step joint.

although they do not include double-step joints. Moreover, for a single notch, Verbist et al. (11) revised design rules by most European Standards, highlighting that the reduction coefficient in shear strength value, due to the heterogeneous shear stress distribution at the tie-end, is only considered by some standards and it is still under study. Verbist et al. (11) also tested different geometries for single step joint on sawn timber. None of the previous works studied heavy timber made from glulam.

Provided this background, studying these assemblies by generating a numerical model, validated through experimental real size test, which allows, as main objective, analysing the stress state of the assemblies, was found of high scientific interest. In particular, the numerical simulation carried out, will help to improve the knowledge of the stress distribution at the tie-end. The previous goal to obtain the main objective is to contrast and validate the numerical results with the experimental ones, through load-displacement and load-strain diagrams obtained by extensometry. Another partial goal of this work is to compare the failure load of the joints tested and values from the theoretical calculation. In addition, this research was conducted to observe real size pieces when similar loads to those 
produced in buildings were applied. This aspect should be emphasised because most of the studies performed until now did not focus on heavy timber structures.

\section{THEORETICAL DESIGN OF THE JOINT}

The geometrical definition of the double-step joint is needed for conducting the experimental tests, as there exist different ways to manufacture it. The Eurocode 5 (EN 1995-1-1:2016) (12) does not suggest any geometrical definition for double-step joints. Therefore, the Spanish Technical Building Code for Timber Structures (CTE DB SE M:2009) (13) was chosen. In this code, a right-angle rear notch $\left(90^{\circ}\right)$ starting from the middle of the rafter cross-section and a frontal step in the bisectrix are considered, Figure 3.

The joint design requires verifying the compression stresses in the notches' surfaces considering the angle between the stress and grain, as well as checking the shear stresses, i.e., checking the step depth (t) and the length (a) of the shearing path, Figure 3 , as indicated in Villar et al. (5), for each step. Besides, two reduction coefficients must be considered. The $k_{c r}$, a reducer coefficient of the member width (b), takes into account the influence of possible cracks on the shear strength along the grain $\left(k_{c r}=0.67\right.$ for glulam (12)). And the $k_{v, \text { red, }}$ a reducer coefficient taking into account the heterogeneous shear stress distribution at the tie-end, is used, because the theoretical calculation considers a uniform distribution of the stress along the shearing path. Eurocode 5 (12) or CTE DB SE M does not clearly suggest the use of the $k_{v, \text { red }}$ factor. However, the Dutch National Annex to Eurocode 5 (14) or the Swiss standard SIA 265 (15) suggests the use of $k_{v, r e d}=0.8$, whereas other authors suggest even lower values: $0.4-0.5$ (16), or 0.45 for a halved and tabled tenoned scarf joint study (17). Desing equation [1] introduces these coefficients in the theoretical calculation when checking the shearing path stresses:

$$
F_{h}<k_{v, r e d} \cdot f_{v, k} \cdot \frac{k_{\mathrm{mod}}}{\gamma_{M}} \cdot b \cdot k_{c r} \cdot a
$$

where:

$\mathrm{F}_{\mathrm{h}}$ horizontal component of the rafter axial load $\mathrm{f}_{\mathrm{v}, \mathrm{k}}$ characteristic shear strength $\left(\mathrm{N} / \mathrm{mm}^{2}\right)$

$\mathrm{k}_{\text {mod }}$ modification factor for duration of loading and moisture content

$\gamma_{\mathrm{M}}$ partial coefficient of the material

(a), (b) and the reducer coefficients $\left(k_{v, \text { red }}, k_{c r}\right)$ are the aforementioned terms.

\section{MATERIALS AND METHODS}

\subsection{Test setup}

Figures 4 and 5 illustrate the test setup for the transmission of a monotonic axial load by a hydraulic actuator to the double-step joint. The tie-beam, $1650 \mathrm{~mm}$ in length and $120 \times 240 \mathrm{~mm}\left(28,800 \mathrm{~mm}^{2}\right)$ in cross-section, was placed horizontally. The rafter, with $120 \times 200 \mathrm{~mm}\left(24,000 \mathrm{~mm}^{2}\right)$ in cross-section and $950 \mathrm{~mm}$ in length, was placed in a $30^{\circ}$ angle, which is normally seen in timber frames in large or medium span roofs. These cross-sections corresponded to a king-post truss with $10 \mathrm{~m}$ of span for service class I. The horizontal beam was anchored according to the traction for avoiding a constraint at the tie-end from interfering with the stress behaviour of the timber in the area of the notches.

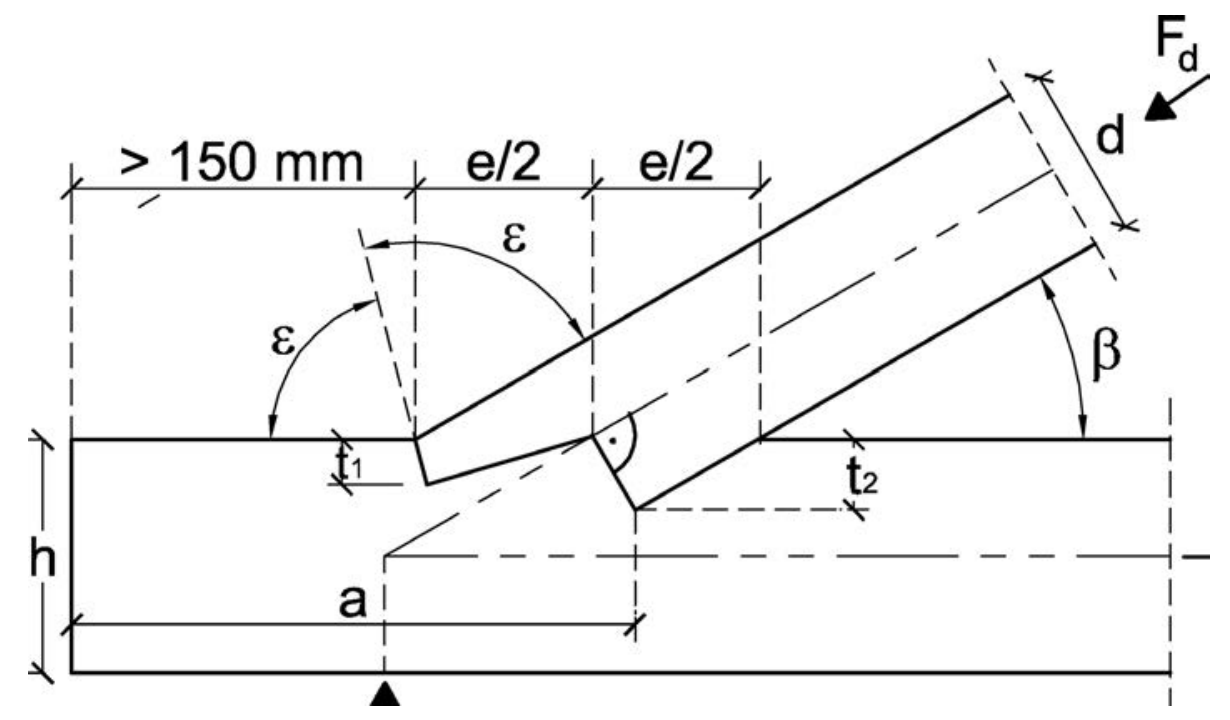

FIGURE 3. Double-step joint, geometrical definition. Taken from the CTE DB SE M. 


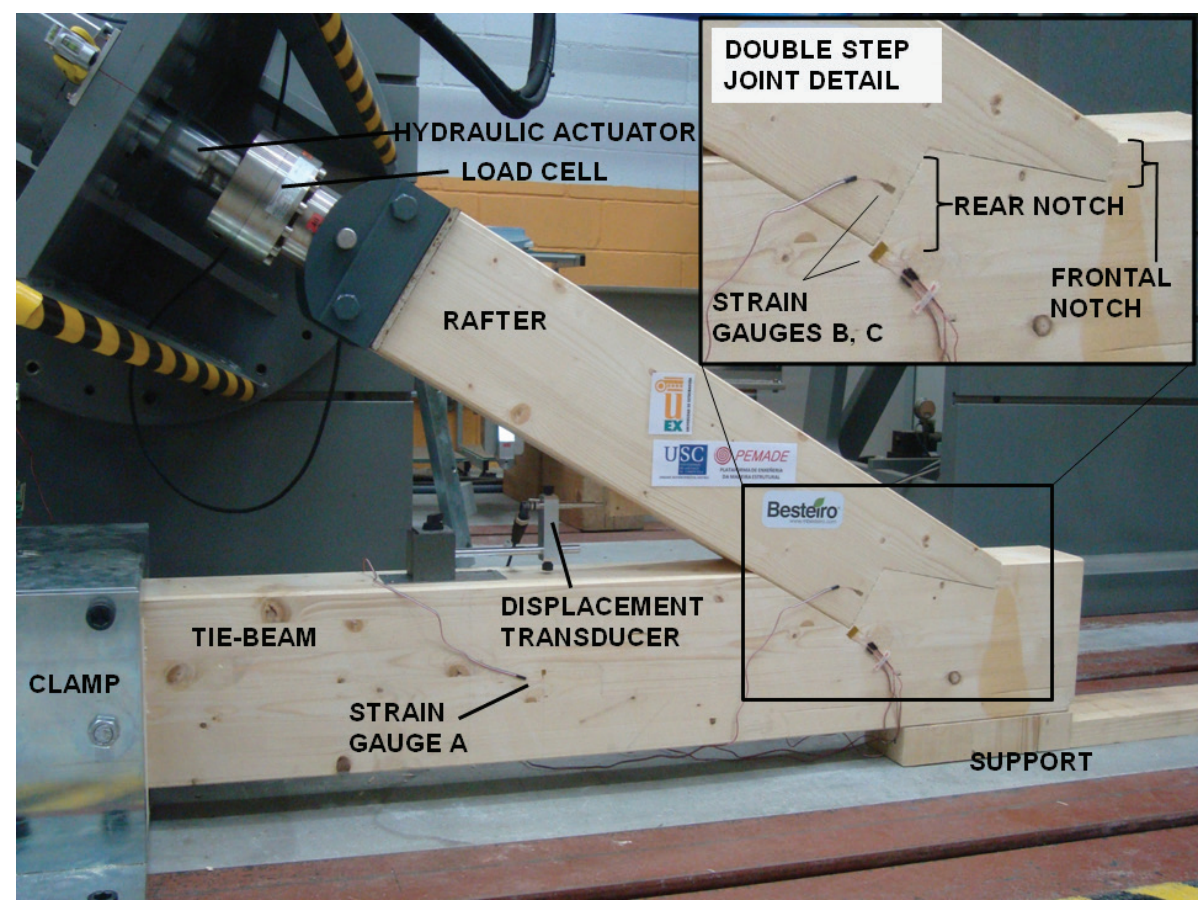

Figure 4. Test setup, with the detail of the double-step joint area.

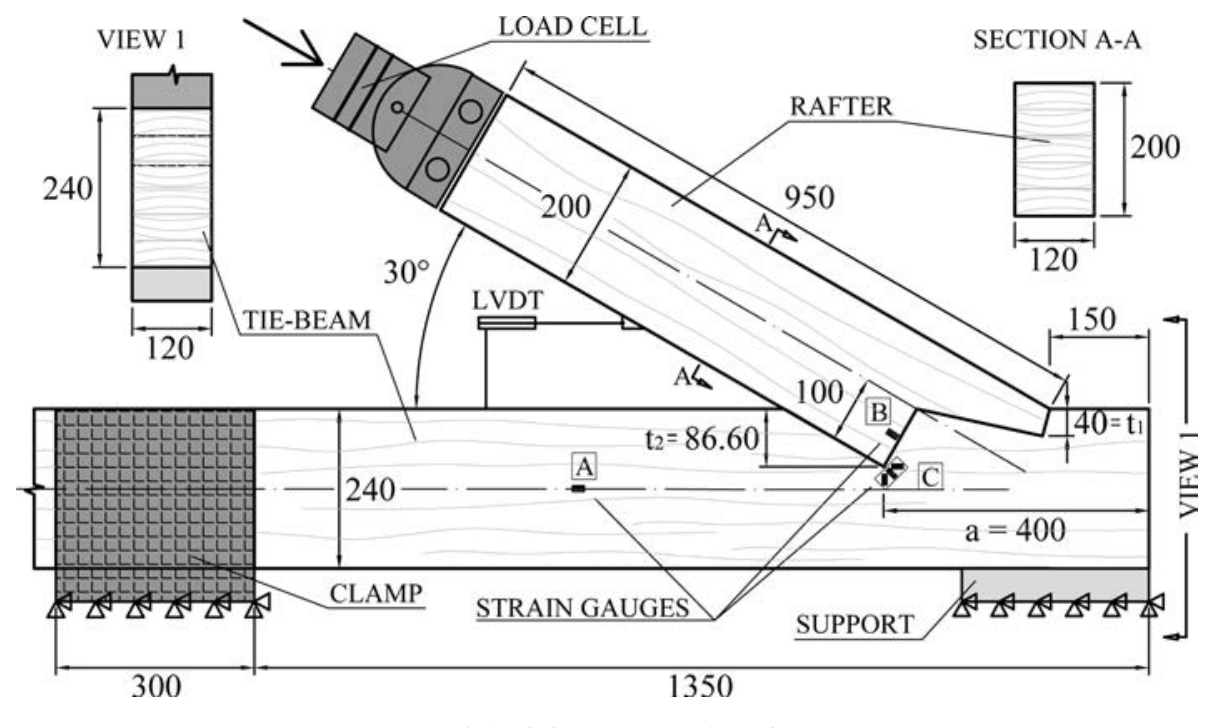

FIgURE 5. Geometry of the joint (mm) and strain gauges arrangement.

The dimensions of the joints that were tested, with the cross-sections previously mentioned, taking account of the geometrical recommendations of the CTE DB SE M standard, are those shown at Figure 5. An $86.6 \mathrm{~mm}$ rear heel depth $\left(\mathrm{t}_{2}\right)$ with a $400 \mathrm{~mm}$ chord shear length (a) from the rear notch is established. Thus, it complies with the minimum length of 150 $\mathrm{mm}$ at the final upper part of the tie-beam. A 40 $\mathrm{mm}$ front heel depth $\left(\mathrm{t}_{1}\right)$ is also established, corresponding to the sixth part of the tie-beam height $(\mathrm{h})$, which is the maximum value indicated by this standard for the front notch depth. Spruce (Picea abies L. Karst) glulam of strength class GL24h was used, thus Standard EN 14080:2013 (18) was considered to the theoretical calculation, specifically shear strength parallel to the grain $\mathrm{f}_{\mathrm{v}, \mathrm{k}}=3.5 \mathrm{Nmm}^{-2}$ and the compressive strengths parallel $\mathrm{f}_{\mathrm{c}, 0, \mathrm{k}}=24 \mathrm{Nmm}^{-2}$ and perpendicular $\mathrm{f}_{\mathrm{c}, 90, \mathrm{k}}=2.5 \mathrm{Nmm}^{-2}$ to the grain.

Figure 5 shows the arrangement for data collection: LVDT- Linear variable differential transformer, 
to measure the relative horizontal displacements rafter - tie-beam; A-Simple strain gauge positioned horizontally for recording the strain parallel to the fibre away from the area with high stress concentration; B- Strain gauge facing the rear notch, measuring the strain parallel to the fibre; $\mathrm{C}$ - Triple strain gauge at the tie-beam next to the bottom corner of the rear step for recording the strain parallel, normal and at $45^{\circ}$ to the fibre. The strain gauges were placed on both sides of the beams.

The object of the triple strain gauges placed at $\mathrm{C}$ is, in addition to reading the single strains commented above, allowing to indirectly study the concentration of shear stresses produced in the shearing path, close to the rear step.

The specimens tested come from glued laminated beams and its axis coincided with the longitudinal direction (L), whereas at the joint plane, it made no sense talking about a unique normal direction but an average between the radial ( $\mathrm{R}$ ) and tangential (T). This is due to the arrangement of the planks that configure them and the placement of the strain gauges, which are logically placed at the sides of the pieces and not inserted at the centre or the material axis. We will consider a plane stress state where all stresses are within the $\mathrm{L}-\mathrm{R}$ plane just for the effect of the following mathematical expression, Eq. [2]. However, it must be taken into account that the radial and tangential properties would compound the $\mathrm{R}$ direction as it will be simulated in the numerical models as well, transverse isotropy is commonly used in timber, especially for glulam beams. The strains measured for each gauge of the rosette (gauges in three directions) are related through means of the expression [2] $(19,20)$ :

$$
\varepsilon=\varepsilon_{L} \cdot \cos ^{2} \alpha+\varepsilon_{R} \cdot \sin ^{2} \alpha+\gamma_{L R} \cdot \sin \alpha \cdot \cos \alpha
$$

Considering $\alpha=45^{\circ}$, with the three strains of the triple gauge, an angular distortion is obtained, $\gamma_{\mathrm{LR}}$, at Eq. [1]. This, along with the longitudinal $\varepsilon_{\mathrm{L}}$ and radial $\varepsilon_{\mathrm{R}}$ strains and through the flexibility matrix of the timber, allows obtaining the stress matrix and therefore, the shear stress $\tau_{\mathrm{LR}}$. The use of Eq. [2] requires that the specimen has a linear elastic behaviour in the area where the rosette has been placed. This assumption is acceptable because of the results that will be shown in section 4.2, Figures 10 and 11 .

The stress $\tau_{\mathrm{LR}}$ obtained is compared with the theoretically calculated value assuming a uniform shear stress distribution at the tie-end for discovering the stress concentration factor, SCF (ratio between peak stress and nominal stress) in that area.

Three double-step joints were tested to compare the numerical models with the measures obtained experimentally. The use of large timber cross-section limited the number of tests performed, although it is within the normal range of specimens, for a specific geometry, tested in other works referenced in section 1 to compare with numerical models. Specimens were conditioned at $20 \pm 2{ }^{\circ} \mathrm{C}$ and $65 \pm 5 \%$ humidity according to EN 408:2011+A1:2012 (21); which corresponds to a moisture content about $12 \%$ for softwood timber and therefore service class I. The humidity values were checked before each test.

\subsection{Numerical models}

\subsubsection{Description of the numerical simulation model}

The modelling strategy is similar to that used by the authors for the reverse step joint (5), so this section provides a summary and a more detailed explanation can be found at this reference. The dimensions of the pieces and the transmission of the force are compatible with a plane stress analysis. It is a $2 \mathrm{D}$ analysis considering the same thickness as the width of the cross-section. A $2 \mathrm{D}$ elastic orthotropy was applied to the finite elements that constitute the material. For perpendicular direction to the fibre, the elastic properties values can be assumed as the average of those corresponding to the radial and tangential ones, especially for glulam beams due to the layout of the planks. This simplification is acceptable for this type of model$\operatorname{ling}(3,5,7,17,22,23)$ and perpendicular isotropy lowers the computational cost, as some authors point out (22). Tests were developed within the elastic range. Plasticity will not be reached, as it will be checked in the test results, and corroborated by the stresses observed at failure, which will be later detailed at the section 4 . The linear elastic constitutive law of the timber is widely accepted by the scientific community while analysing timber joints within the conditions here exposed (3, 5, 17, 24-26).

The joint tested was numerically modelled by applying finite element methods (FEM) using the software ANSYS (27). The mesh was designed to be as uniform as possible, providing more density in those areas with a higher stress gradient to ensure the precision of the simulation, Figure 6. A preliminary sensitivity study was performed to appreciate the effect of the element sizes on the accuracy of the results in connection with the computational cost. Consequently, at the joint area, the maximum size of the finite element was $5.5 \mathrm{~mm}$, with a minimum of $2.6 \mathrm{~mm}$. Regarding the boundary conditions, the model considered the real test conditions: load, the anchored with respect to traction and the support of the tie-beam on a timber block. The model simulated the friction between contact surfaces; detailed explanations of the method followed in the friction simulation is described in previous works (3-5).

In addition, the failure criterion of Tsai-Wu (28) was implemented in the model. Nowadays, 


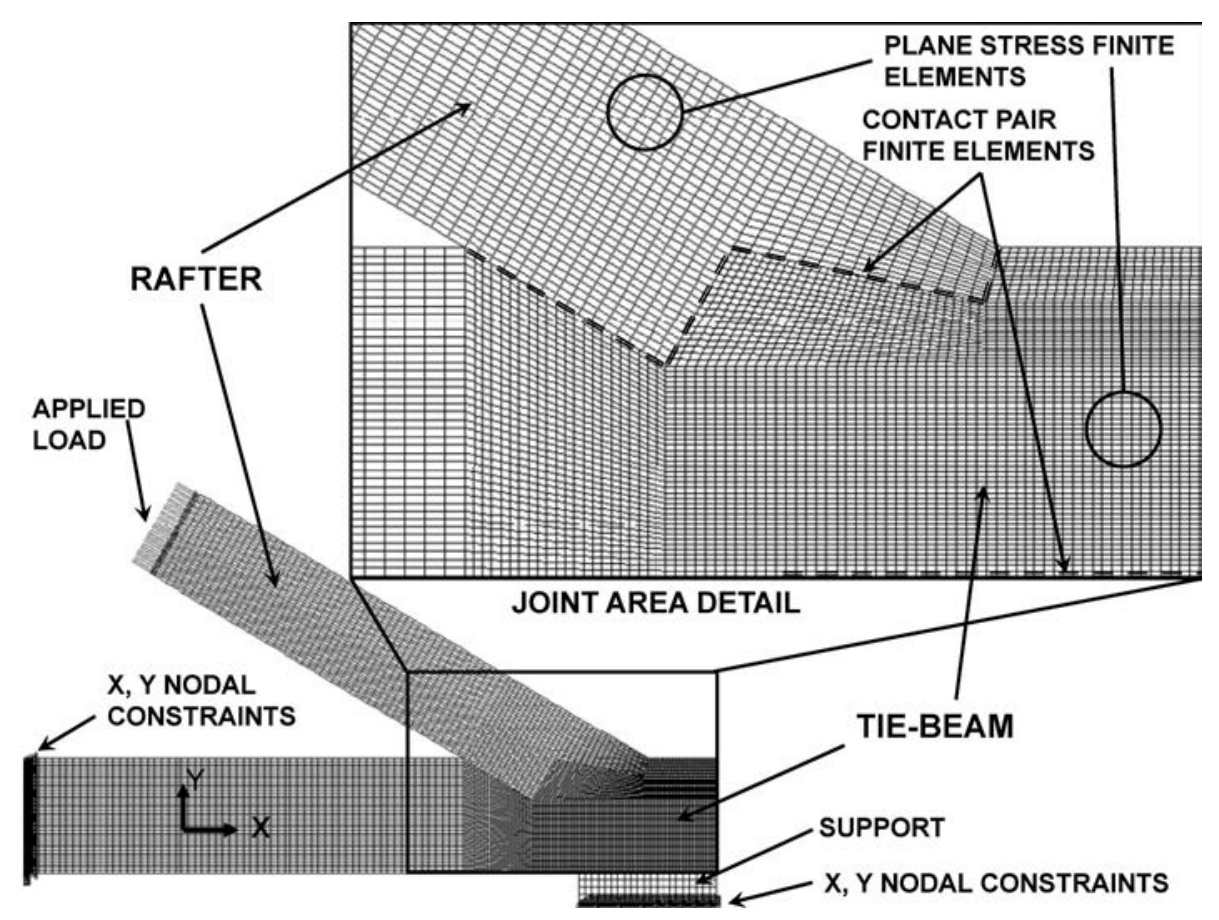

FIGURE 6. Finite element meshing of the model.

this is the extensively used criterion when timber is modelled as a linear elastic-brittle material (29). The analysis conducted assesses the stress combination at nodes depending on Tsai-Wu criterion, where values greater than one imply failure through the FEM simulation. The criterion was implemented iteratively with progressive loading steps. In-depth information on the theory behind this criterion can be found in the references section (28-32) and detailed explanation related to its implementation on numerical models can be found at the reference number (5).

\subsubsection{Material parameters for the numerical simulation}

On one hand, a literature review was carried out, highlighting the mechanical properties' values for spruce wood provided by Schmidt and Kaliske (33) and Dahl (34) in numerical simulations. In any case, other interesting references can be found in the references section $(22,32,35)$. The material properties taken from the international literature are the same as the ones described by the authors for spruce in previous works (5), the elastic parameters are assumed as (all parameters are mean values):

$$
\begin{aligned}
& E_{r}=820 \mathrm{~N} \mathrm{~mm}^{-2} ; G_{r t}=40 \mathrm{~N} \mathrm{~mm}^{-2} ; v_{r t}=0.50 \\
& E_{t}=430 \mathrm{~N} \mathrm{~m}^{-2} ; G_{t l}=730 \mathrm{~N} \mathrm{~mm}^{-2} ; v_{l t}=0.48 \\
& E_{l}=13200 \mathrm{~N} \mathrm{~mm}^{-2} ; G_{r l}=660 \mathrm{~N} \mathrm{~mm}^{-2} ; v_{l r}=0.42
\end{aligned}
$$

And the strengths (all parameters are mean values):

$f_{t, l}=65.50 \mathrm{~N} \mathrm{~mm}^{-2} ; f_{c, l}=-50.30 \mathrm{~N} \mathrm{~mm}^{-2} ; f_{\mathrm{v}, t}=5.34 \mathrm{~N} \mathrm{~mm}^{-2}$ $f_{t, r}=3.75 \mathrm{~N} \mathrm{~mm}^{-2} ; f_{c, r}=-6.00 \mathrm{~N} \mathrm{~mm}^{-2} ; f_{v, r l}=6.34 \mathrm{~N} \mathrm{~mm}^{-2}$ $f_{t, t}=2.79 \mathrm{~N} \mathrm{~mm}^{-2} ; f_{c, t}=-6.00 \mathrm{~N} \mathrm{~mm}^{-2} ; f_{v, r t}=1.83 \mathrm{~N} \mathrm{~mm}^{-2}$

On the other hand, longitudinal $\mathrm{E}_{1}$, radial $\mathrm{E}_{\mathrm{r}}$ and tangential $E_{t}$ moduli of elasticity were also obtained experimentally. Six small prismatic specimens were cut from the notches area in each test, following the main orthotropic directions. Ultrasound techniques (ultrasonic pulse velocity test) allow the elastic constants to be determined through several transformations, once the velocity of the wave, the moisture content and the density of the tested piece are known. The ultrasonic wave pulser was equipped with longitudinal and transverse wave transducers with $1.0 \mathrm{MHz}$ nominal frequency, which was suitable for small specimens. Further information concerning the estimation of elastic properties by means of ultrasound techniques is detailed in the references section (36-40). Mean values were:

$E_{l}=16974 \mathrm{~N} \mathrm{~mm}^{-2}($ variation coefficient $-\mathrm{CoV}(\%): 10.5)$

$E_{r}=1643 \mathrm{~N} \mathrm{~mm}^{-2}(\mathrm{CoV}(\%): 18.7)$

$E_{t}=670 \mathrm{~N} \mathrm{~mm}^{-2}(\mathrm{CoV}(\%): 22.9)$

Because these values, derived from timber of the tested joints, were slightly above those mentioned 
in the literature, they were also used in the FEM models.

For each joint test, three timber samples were extracted from the tie-end and shear tests were conducted in the same failure mode observed at the joint. Shear strength parallel to the fibre was obtained due to its governance in the failure of this kind of traditional joints. The testing procedure was the Spanish Standard UNE 56543 (41), which is similar to ASTM D143:14 (42) that is referred to the notched shear block test. The average results were: maximum shear stress of the test $8.90 \mathrm{~N} \mathrm{~mm}^{-2}$ with a nominal shear stress of $4.45 \mathrm{~N} \mathrm{~mm}^{-2},(\mathrm{CoV}(\%)$ : 13.8).

The static friction coefficient must be consider to simulate the contact. The values found in the literature for carpentry joints range among 0.5 (24), 0.3 (7) to 0.24 for Scots pine in surfaces perpendicular to the grain (43). However, Crespo et al. (44) obtained a value of 0.467 for Picea abies glulam timber in transverse cuts to the grain. This last one was finally chosen in this work.

\section{RESULTS AND DISCUSSION}

\subsection{Failure load and theoretical values}

The mode of failure was, for all tests, by shear crack, Figure 7. Neither failure by crushing due to compression stress nor plastic deformation in any area of the contact faces was observed. The shear crack was produced according to the Modus II RL, where the nomenclature used (45) was as follows: "II"- shear by stress parallel to the crack surface and parallel to the propagation of the crack tip; "RL"- the crack plane normal to $\mathrm{R}$ direction, with the crack front advancing in the $\mathrm{L}$ direction. The failure takes the form of semi-brittle behaviour, i.e., it occurs very quickly once crack propagation has taken place (45). The skew angle $\left(30^{\circ}\right)$ selected in these tests contributed to getting a break by shearing. Thus, from the shear failure observed, it could be checked that the failure mode and the way it suddenly happened, i.e., brittle failure, is in accordance with Verbist et al. (11) and Villar et al.'s (5) observations for these angles.

It should be highlighted that the failure is produced by the shearing that originated at the rear notch, i.e., bottom shear path. This demonstrates the suitability of checking the length (a) at this point according to CTE DB SE M. Nevertheless, the geometry provided there prevents a greater load distribution between both steps. Indeed, the rear heel depth is designed from the middle of the incident cross-section, leading to overloading of this heel, as the numerical simulation will confirm.

Table 1 illustrates the rafter axial load and the related failure modes for the tests conducted. It was observed an acceptable variation coefficient $\mathrm{CoV}$ considering the variability that exists in this material. The experimental failure load increased around $19.5 \%$ with respect to the reverse step joint studied in Villar et al. (5), where similar cross-section beams were considered, mainly due to a longer shearing path originated at the rear notch of the double-step joint.

Table 2 shows the maximum force at the rafter, for the lower shear path failure, using Eq.[1] with GL24h and service class I, and the experimental increase with respect to these theoretical results. Furthermore, Table 2 allows comparison between the different values for the reducer coefficient $k_{v, \text { red }}$ as indicated in the section 2. Test values exceeded the theoretical calculation, ranging between $71 \%$ and $280 \%$ of the estimated theoretical values. To study the influence of $k_{v, \text { red }}$ factor related to the heterogeneous shear stress distribution, Table 2 also shows the results that would be obtained if $k_{c r}=1$. In this case, the experimental result exceeded the theoretical value only by $14.5 \%$ when $k_{v, r e d}$ was also neglected $\left(k_{v, \text { red }}=1\right)$. This would be connected with the fact that theoretical calculation considered a uniform distribution of shear stress along the shearing path (up to $8 \mathrm{t}$ according to German National Annex to Eurocode 5 (46)), from the rear notch a great chord

TABLE 1. Applied force, when the failure occurs and the average experimental failure load $\left(\mathrm{F}_{\mathrm{E}}\right)$.

\begin{tabular}{|c|c|c|c|c|}
\hline $\begin{array}{l}\text { Test } \\
\text { number }\end{array}$ & $\begin{array}{c}\text { Rafter axial } \\
\text { load }(\mathbf{k N})\end{array}$ & $\begin{array}{l}\text { Failure } \\
\text { mode }\end{array}$ & $\begin{array}{c}\text { Mean value, } \\
F_{E}(k N)\end{array}$ & $\operatorname{CoV}(\%)$ \\
\hline 1 & 134.2 & $\begin{array}{l}\text { Shear } \\
\text { crack }\end{array}$ & \multirow{3}{*}{160.0} & \multirow{3}{*}{14.2} \\
\hline 2 & 168.5 & $\begin{array}{l}\text { Shear } \\
\text { crack }\end{array}$ & & \\
\hline 3 & 177.3 & $\begin{array}{l}\text { Shear } \\
\text { crack }\end{array}$ & & \\
\hline
\end{tabular}

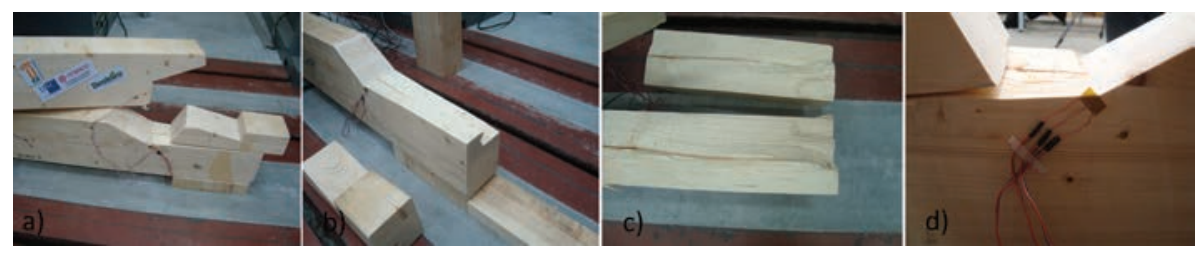

FIgURE 7. a, b) Shear crack in tie-beams; c) Shear surfaces after failure; d) Details. 
TABLE 2. Theoretical calculation of rafter axial failure loads $\left(\mathrm{F}_{\mathrm{T}}\right)$, and the increase $(\Delta)$ of the average experimental failure load value $\left(\mathrm{F}_{\mathrm{E}}=160 \mathrm{kN}\right)$ with respect to those theoretical loads.

\begin{tabular}{|c|c|c|c|c|}
\hline \multirow[b]{2}{*}{$\boldsymbol{k}_{v, \text { red }}$} & \multicolumn{2}{|c|}{$k_{c r}=0.67$} & \multicolumn{2}{|c|}{$k_{c r}=1$} \\
\hline & $\begin{array}{l}\text { Theoretical rafter } \\
\text { axial load } \mathrm{F}_{\mathrm{T}}(\mathrm{kN})\end{array}$ & $\begin{array}{c}\Delta(\%) \text { of } F_{E}(160 \mathrm{kN}) \\
\text { with respect to } F_{T}\end{array}$ & $\begin{array}{l}\text { Theoretical rafter } \\
\text { axial load } \mathrm{F}_{\mathrm{T}}(\mathrm{kN})\end{array}$ & $\begin{array}{c}\Delta(\%) \text { of } F_{E}(160 \mathrm{kN}) \\
\text { with respect to } F_{T}\end{array}$ \\
\hline 1 & 93.6 & 71.0 & 139.7 & 14.5 \\
\hline 0.8 & 74.9 & 113.7 & 111.8 & 43.2 \\
\hline 0.45 & 42.1 & 280.0 & 62.9 & 154.5 \\
\hline
\end{tabular}

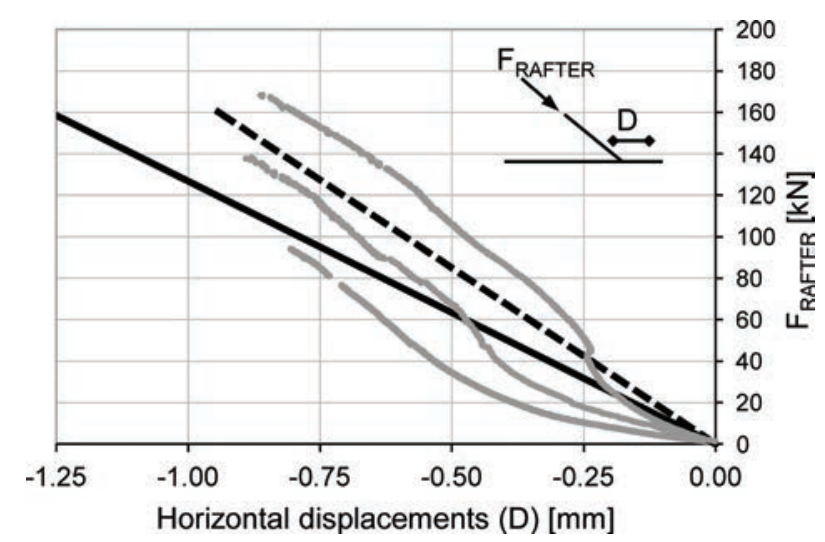

FIGURE 8. Force-displacement diagrams of the experimental investigation for LVDT transducer ( ) and FEM simulation: ( $)$ with elastic (E) values from the literature, $(\boldsymbol{\square} \boldsymbol{\square})$ with E experimental values.

shear length existed, which increased the theoretical result. However, as will be checked later by numerical simulation, shear stress is much higher at the beginning of the chord shear length, whereas the furthest areas represent a small contribution to strength. Therefore, during the test, after the shear strength has been overcome at this initial point of the chord, a crack appeared that rapidly advanced producing the failure. This circumstance was considered by a reducer coefficient applied to shear strength in standards such as Dutch National Annex to Eurocode 5 (14) or Swiss standard SIA 265 (15) as indicated at the section 2. However the use of this reduction coefficient is being currently studied.

\subsection{Experimental curves and FEM results}

Diagrams in this section will illustrate the force applied to the rafter vs. the strain at the locations of the gauges, and the force vs. displacement collected by the LVDT. Moreover, each figure includes the numerical diagrams, both with elastic parameters from literature and those obtained from the members tested. The large surface area of the crosssections resulted in low strains but using highly accurate strain gauges allowed a satisfactory data collection.

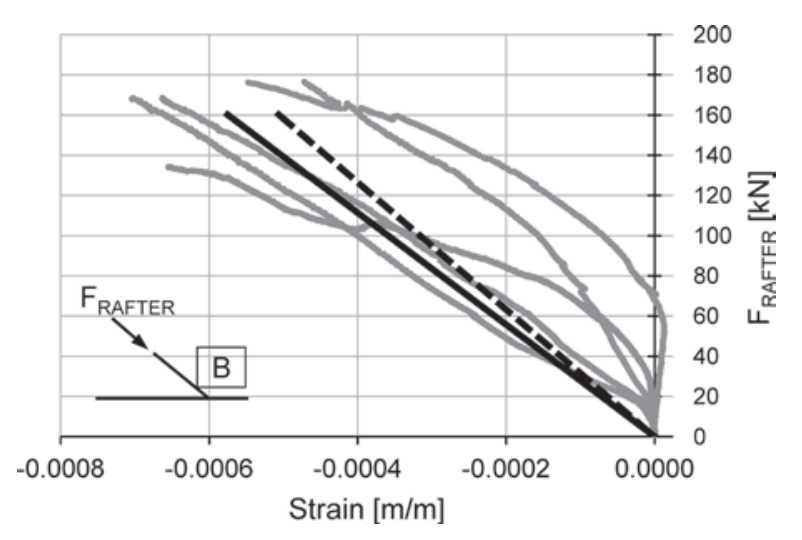

FIGURE 9. Comparison between experimental load-strain graphics for (B) strain gauges ( ) and FEM simulation: ( ) with elastic (E) values from the literature, $(\square-a)$ with E experimental values.

Figure 8 shows the rafter - tie-beam relative horizontal displacements vs. rafter load. Before reading $1 \mathrm{~mm}$ of displacement, transducers (LVDT) were removed to protect them from damage when failure leaves the rafter unsupported. Experimental diagrams start with a curved shape due to a continuous rise in the slope. This nonlinear behaviour was related to the initial fit between joint members as pointed out by Feio et al. (6) and Villar et al. (5); after that, a linear elastic stretch was observed. Numerical simulations displayed linear elastic diagrams whose slopes fitted well to experimental ones once the initial phase had been overcome. This correlation was particularly fine using moduli of elasticity values obtained from the timber pieces in the FEM diagrams. The displacements indicated by the FEM models, corresponding to $160 \mathrm{kN}$ (mean value of the experimental failure loads), were small, ranging from $0.943 \mathrm{~mm}$ for simulation with $\mathrm{E}$ experimental values, to $1.263 \mathrm{~mm}$ for the diagrams with literature values.

Figure 9 shows the points for B strain gauges facing the rear notch. The initial fit can be clearly observed, coherent with Figure 8 . Thus, that fact that this notch surface needs some time to begin working (vertical section of the diagrams) is noted. During that time, the whole load is being 
transmitted only through the front notch surface, until the rear notch surface takes whole contact and collaborates, then compression begins to be appreciated (negative values of strain, shortening). Some authors suggest a gap in the contact surface of the front notch to avoid this situation; Bocquet (47) suggests introducing a gap $2 \mathrm{~mm}$ wide. The rear notch begins to collaborate in most cases before $30 \mathrm{kN}$, Figure 9, which would correspond to a displacement between 0.25 and $0.5 \mathrm{~mm}$ in Figure 8, which is close to the stabilisation of the load-displacement diagrams. This indicates that, under the conditions of this study, the gap will be advisable but smaller than that recommended by Bocquet.

The numerical models' diagrams are also represented, both with $\mathrm{E}$ values from the literature and specimens. The numerical representation ends at $160 \mathrm{kN}$ (average experimental failure value). FEM models fit well considering the material variability usually seen in timber tests. In some cases, it is better appreciated if the numerical lines move parallel to the point where the data corresponds to the beginning of the loading conditions and start to measure deformation. Finally, there was a sudden failure and the following record of the gauges after failure, next to the strain value 0 , indicated an elastic recovery of the material in this area close to the notch. This behaviour is consistent with that reported by Villar et al. (5).

The triple gauges $\mathrm{C}$, the rosette located at the lowest part of the rear step, Figure 5 and $7 d$, provide the measurement of the parallel strain, the normal one and the one at 45 degrees to the grain. Figures 10 and 11 display the plots for both strain normal and parallel, together with the FEM graphs. These gauges are situated quite near to the meeting between contact faces of the rear notch. Because of this geometrical singularity, sometimes, these measurements correspond to irregular paths. However, once the contact was stabilised, a linear behaviour was appreciated during a significant part of the tests. It is just next to the failure when some of the gauges suffer a degradation and the values they provide are more erratic. As for the results obtained by FEM simulation, a good fit is observed, especially when the elastic constant values directly derived from the pieces tested are used. This would indicate that even in a complex area that has singularities, the numerical model fits well. The parallel deformation to the fibre is a positive strain, which is lengthened and produced by the tension reached in this area of the tie-beam, whereas in the perpendicular direction, a gauge shortening produces negative strain, thus showing compression. It can be appreciated that the great stress concentration in this joint area causes strains one level higher in magnitude with respect to those obtained at the location of B strain gauges.

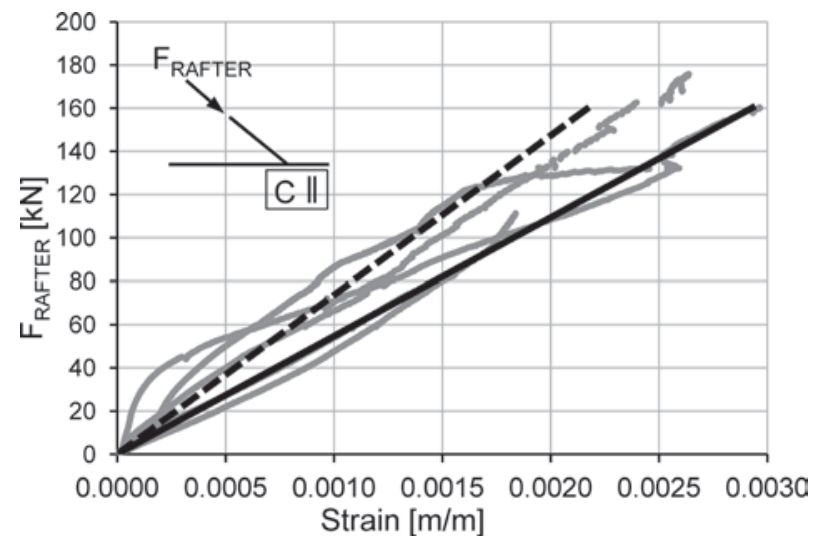

FIGURE 10. Comparison between experimental load-strain graphics for $(\mathrm{C})$ parallel to the grain strain gauge ( $)$ and FEM simulation: (D) with elastic (E) values from the literature, $(\mathbf{-} \mathbf{- a})$ with E experimental values.

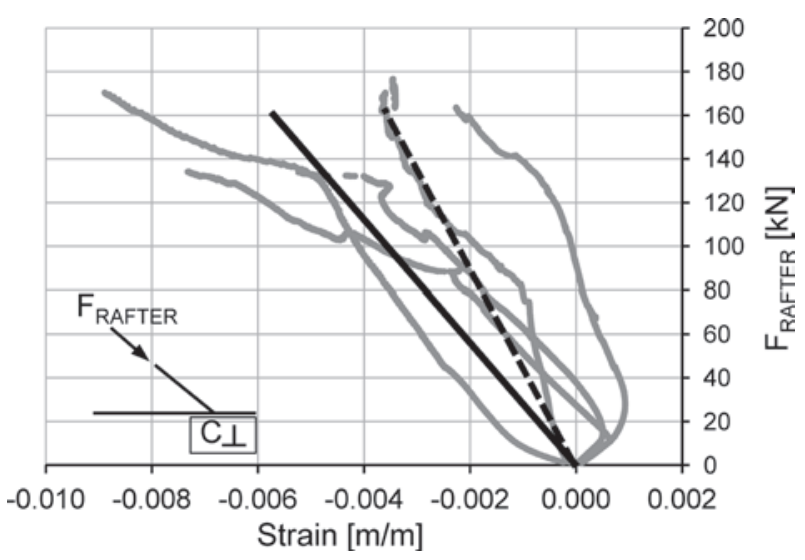

Figure 11. Comparison between experimental load-strain graphics for $(\mathrm{C})$ transverse to the fibre strain gauge ( ) and FEM simulation: ( $(-$ elastic $(\mathrm{E})$ values from the literature, (- - ) with E experimental values.

\subsection{Validation of the models}

The validation was carried out through the measures obtained experimentally, even though the fundamentals of the simulation have already been validated in a previous work (5). First, the outline of the experimental load-displacement and load-strain diagrams, shown at section 4.2, is observed, along with the suitability of the FEM graphs. In all cases, a good correlation has been checked. However, an initial period exists where a fit takes place between the contact fronts, due to the adjustment $(5,6)$, until a steady linear behaviour is reached. This is especially remarkable at the double-step union since two notches need to be adjusted to transmit the load. When steady linear behaviour was achieved, the slopes of the experimental diagrams were acceptably adjusted to the simulation ones. Therefore, it 
can be considered as a graphic validation as performed in similar studies with numerical models $(5,6,22)$. Moreover, in this work, it would be suitable to show this good fit through a mathematical validation by comparing the experimental strain with the FEM model strain. It is necessary to find areas of steady comparisons, i.e. elastic stretch with a regression line showing a $\mathrm{R}^{2}>0.99$. It is strongly recommended that comparisons be conducted at the linear area of the load-strain diagram corresponding to a 10 to $40 \%$ of the highest load reached (21). As a general trend, this condition can be achieved by considering a rafter axial load of $50 \mathrm{kN}$. In this work, both, gauges located far from stress concentration areas and gauges placed close to the special interest areas, were used. This is the case of the notch surfaces or the meeting points, corner, between surfaces as it occurs with the $\mathrm{B}$ and $\mathrm{C}$ gauges. In this way, the reliability of the models for these areas was also verified. Due to the period where fit takes place between the pieces, initial irregular paths were obtained: positive strain values instead of negative ones at the beginning of the tests (Figure 11), vertical load-strain diagrams (Figure 9), or initial nonlinear increase in the slope (Figure 8), which deviated from the steady behaviour where the strain must be zero when the load is zero, too. Therefore, it was necessary to adjust some experimental diagrams with an appropriate strain origin but maintaining the steady linear slope of the elastic area. It is the case for some diagrams for B and C gauges and LVDT transducer. The validation points according to the indicated criteria and the results obtained are shown in Table 3. The FEM strains in this table are derived from the simulation conducted with the elastic values obtained experimentally from samples of the pieces.

Variation coefficients of experimental measurements were acceptable due to the natural variability of timber and their similarity with that of other works published $(5,17,48)$. The greatest $\mathrm{CoV}$ and differences were found at gauges $(\mathrm{C})$. This could be mainly caused by the interaction between the singularity of the corner with the gauge at that point. Table 3 shows that the difference was always lower when variation coefficients of the experimental results were compared to the percentage difference between the FEM and test results. Therefore, it is appropriate to affirm that the simulation fitted well to the test results as indicated in previous works $(5,17)$.

\subsection{Stress behaviour of the joint}

For the study of the tensional state, E values obtained experimentally from samples of the pieces were used. Figure 12 shows the normal stress in the longitudinal direction for a rafter load of 160 $\mathrm{kN}$, which is the mean failure value obtained at the tests. The increased displacement scale allows one to observe that contact between the lower part of the rafter and the tie-beam is almost inexistent. Therefore, they are the notch fronts, especially the rear one that mainly transmits the action of the tiebeam to the rafter. The compression strength in the direction of the fibre did not exceed according to the literature, and was far from reaching the plastic behaviour, which was not detected experimentally. From Figure 12 one can appreciate the strong tension parallel to the axial direction produced at the tie-beam under the rear notch, although it did not imply overcoming ultimate limit states in the experimental study.

Concerning the maximum value reached at the rafter, Figure 13 shows that the maximum stress value for the compression in the grain direction was $-22.09 \mathrm{~N} / \mathrm{mm}^{2}$ at the lower part of the rear front, whereas it was $3.94 \mathrm{~N} / \mathrm{mm}^{2}$ for the tension at the upper corner. These values are lower than those provided in the literature for this material. Increasing the contact surface by means of two notches allows obtaining lower compression values in the grain direction at the rafter than those that would be obtained in a single step joint. If compared with the reverse step joint, analysed in Villar et al. (5), and despite the fact that the final load was around $16 \%$ lower in that study, higher parallel compressions to the grain were obtained in the reverse step joint.

Figure 13 also shows, the normal contact stress distribution at the faces in contact. The stress diagram at the two notch areas are almost uniform, but there is a concentration of tensions at the lower

TABLE 3. Comparison of the average test strain $\left(\varepsilon_{\mathrm{exp}}\right)$ or displacements (for LVDT transducer) and FEM model strain ( $\left.\varepsilon_{\mathrm{FEM}}\right)$, or displacements, for a rafter axial force of $50 \mathrm{kN}$.

\begin{tabular}{lccc}
\hline Validation point & \multicolumn{1}{c}{ CoV $\left(\varepsilon_{\text {exp }}\right)$} & Difference \\
$\mathbf{( \% )}$ & $\varepsilon_{\text {exp }}$ & 25.95 & $6.578 \times 10^{-05}$ \\
\hline A - tie beam - parallel & $5.840 \times 10^{-05}$ & 22.18 & $-1.738 \times 10^{-04}$ \\
B - notch - parallel & $-2.189 \times 10^{-04}$ & 28.04 & -20.60 \\
C - notch corner - parallel & $7.771 \times 10^{-04}$ & 34.99 & -12.66 \\
C - notch corner - perpendicular & $-1.454 \times 10^{-03}$ & 10.35 & $-1.235 \times 10^{-03}$ \\
LVDT - transducer (mm) & 0.2726 & & 0.2943 \\
\hline
\end{tabular}




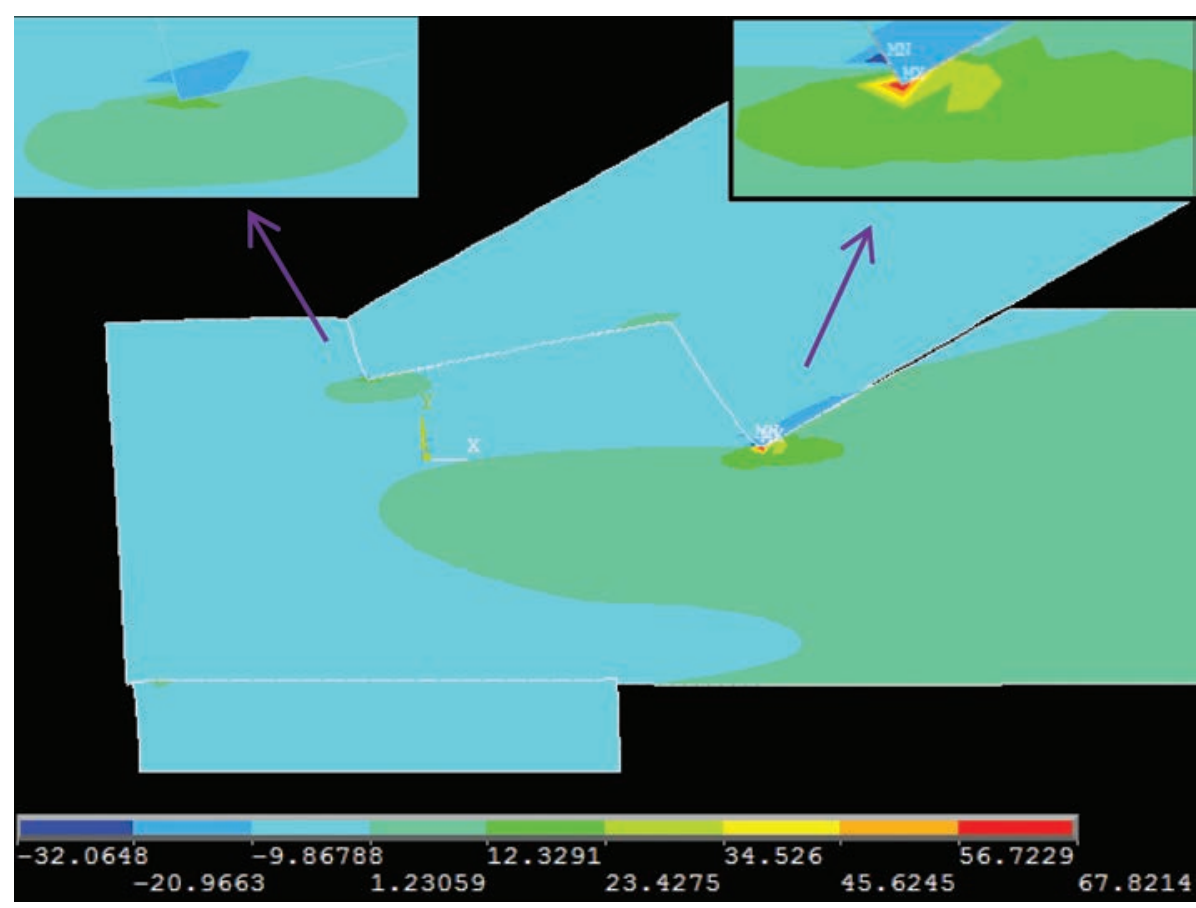

FIGURE 12. Normal stresses $\sigma_{x}\left(\mathrm{~N} / \mathrm{mm}^{2}\right)$ in the grain direction for compression load at the rafter of $160 \mathrm{kN}$. Displacement scale x30.

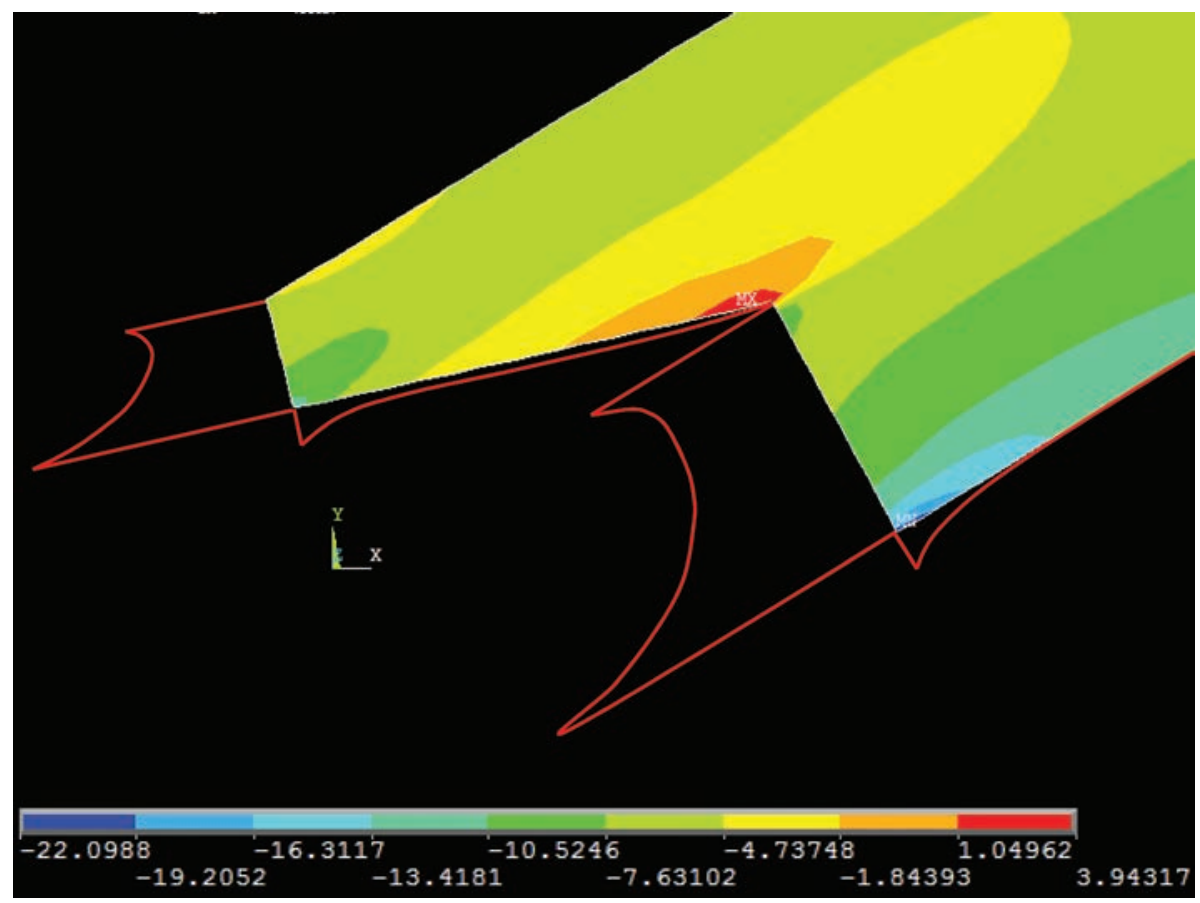

FIgURE 13. Normal stresses $\sigma_{x}\left(\mathrm{~N} / \mathrm{mm}^{2}\right)$ in the fibre direction at the top chord and diagram of the normal contact stress for an axial load of $160 \mathrm{kN}$.

corners. The two other faces, the lower one of the rafter and that of the joint between both fronts, scarcely collaborate at the compression. By integrating the normal stress through the surface of the rear notch surface, the load transmitted by this surface can be determined. In this case, the value obtained was $107.62 \mathrm{kN}$, which represents $67.3 \%$ of the total load of the rafter. This involves a higher distribution of the load in this surface if compared to a distribution of $50 \%$ reported by several authors $(16,49)$. 
This result is logical because of the geometrical definition of the joint according to CTE DB SE M with a rear notch of higher dimensions than the front one. On the other hand, the stresses transverse to the fibre presented neither remarkable results nor values that could compromise the joint stability.

The curve of shear stress at the chord shearing path can be seen in Figure 14 for a rafter axial force of $160 \mathrm{kN}$, the shear stress is concentrated at the chord beginning. This is where the crack originates as it was seen in the tests conducted. It can be observed that, in this point, the shear strength values provided at the literature (Section 3.2.2) are exceeded. In Figure 14, $8.05 \mathrm{~N} / \mathrm{mm}^{2}$ is the stress peak, near $8.90 \mathrm{~N} / \mathrm{mm}^{2}$, which is the value from the shear tests carried out with timber of the joint area. Failure occurs when the crack begins to progress, i.e., stress peak exceeds the strength of the timber at this point.

It could be observed that no significant shear stresses were generated at the front step shear path. However, the principal shear stress distribution from the rear notch was affected as the plot shows an increase under the influence area of the front notch before it becomes zero at the end of the bottom chord shear length.

It is possible to obtain the SCF for a representative point of the linear elastic stretch, as suggested in section 4.3 for a load of $50 \mathrm{kN}$. In this case, the measurements of the triple gauges (C) for $\varepsilon_{\mathrm{L}}$ y $\varepsilon_{\mathrm{R}}$ (Table 4) would be taken and placed within Eq. [2] together with the experimental mean value for $\varepsilon_{45}$, which was $-1.201 \times 10^{-03}(\mathrm{CoV}=32.6 \%)$. Thus, the angular distortion $\gamma_{\mathrm{LR}}=-1.685 \times 10^{-04}$ can be obtained. Using this value within the flexibility matrix, as suggested in section 3.1, the experimental mean shear stress $\tau_{\mathrm{LR}}=-1.92 \mathrm{~N} / \mathrm{mm}^{2}$ could also be determined. The numerical model for a load of $50 \mathrm{kN}$ provides a maximum shear peak of $-2.49 \mathrm{~N} / \mathrm{mm}^{2}$. The percentage difference is $+29.6 \%$, which is within the common $\mathrm{CoV}$ for timber. In addition, it must be taken into account that the stress concentration obtained with simulation is punctual, whereas the strain gauge covers an effective area of measurement, thus reducing its value. Hence, regarding the shear stress, the FEM simulation can be taken as representative of the tests performed. The theoretical uniform stress for $50 \mathrm{kN}$ (horizontal component, $\mathrm{F}_{\mathrm{h}}=43.30 \mathrm{kN}$ ), would be $\tau_{\mathrm{v}}=0.90 \mathrm{~N} / \mathrm{mm}^{2}$, and the concentration factor would be as follows [3]:

$$
\begin{aligned}
& S C F_{E X P 50 k N}=\frac{1.92}{0.90}=2.13 \\
& S C F_{F E M ~ 50 k N}=\frac{2.49}{0.90}=2.77
\end{aligned}
$$

The model $\left(S C F_{F E M}\right)$ provided a value $30 \%$ higher than the experimental one $\left(S C F_{E X P}\right)$.
For the failure load $(160 \mathrm{kN})$, if we want to obtain the SCF, the value of the horizontal component might be taken as $\mathrm{F}_{\mathrm{h}}=138.56 \mathrm{kN}$, whereas the theoretical uniform shear stress would be $\tau_{\mathrm{v}}=2.89$ $\mathrm{N} / \mathrm{mm}^{2}$. As indicated above, the shear stress peak, obtained with FEM, was $8.05 \mathrm{~N} / \mathrm{mm} 2$, Figure 14 . Therefore, with these data, the SCF is as follows [4]:

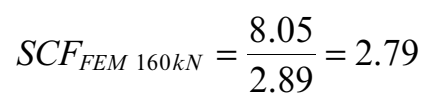

which was similar to that obtained for $50 \mathrm{kN}$ $\left(S C F_{F E M 50 k N}=2.77\right)$. It was not possible to obtain the SCF experimentally at the moment when a failure occurred because of the irregular measurements of the gauges due to its deterioration.

These results confirm the distribution presented in Figure 14, a triangular diagram with a slope increase to the contact face, which represents an SCF greater than two. This distribution is in accordance with other studies $(3,5,49,50)$, a half hammock shape as reported by Verbist et al. (11), but even more intense when reaching the corner side in the shear path. These results for the SCF indicates that the theoretical uniform shear stress is around 0.36 $\left(S C F_{F E M}=2.77-2.79\right)$ and $0.47\left(S C F_{E X P}=2.13\right)$ of the highest shear stress reached. Therefore, using a reduction coefficient of the shear strength in regard to the stress distribution, is strongly recommended. Moreover, the relationship observed between the uniform shear stress at failure $\left(2.89 \mathrm{~N} \mathrm{~mm}^{-2}\right)$ and the literature shear strength, approximately equal to 0.5 , as well as that between the uniform shear stress at failure and the shear strength obtained in notched shear block tests $(0.65)$, pointed out that $k_{v, \text { red }}$ factor would be near the more restrictive values suggested by some authors $(16,17)$.

It is also of interest to compare the value of the total shear stress obtained as the horizontal force $(138.564 \mathrm{kN})$ with that obtained by numerical simulation for the bottom shear path (from the rear notch). That is the integral of the shear distribution surface plotted at Figure $14(137.440 \mathrm{kN})$, which corresponds to a difference of only $0.8 \%$. This would correspond with what is held back by the friction produced between the lower face of the rafter and the tie-beam.

On the other hand, if compared with the single step joint for the same horizontal force, a single front notched joint would require increasing the tie end over the minimum $150 \mathrm{~mm}$. Furthermore, the reverse step joint, studied in Villar et al. (5), would not have sense for this horizontal force due to the necessary extension of the tie beam beyond the meeting point with the rafter. In addition, at the same time the favorable effect of the frontal notch is eliminated.

The model also allows the plotting of the failure rates according to Tsai-Wu criterion, Figure 15. 


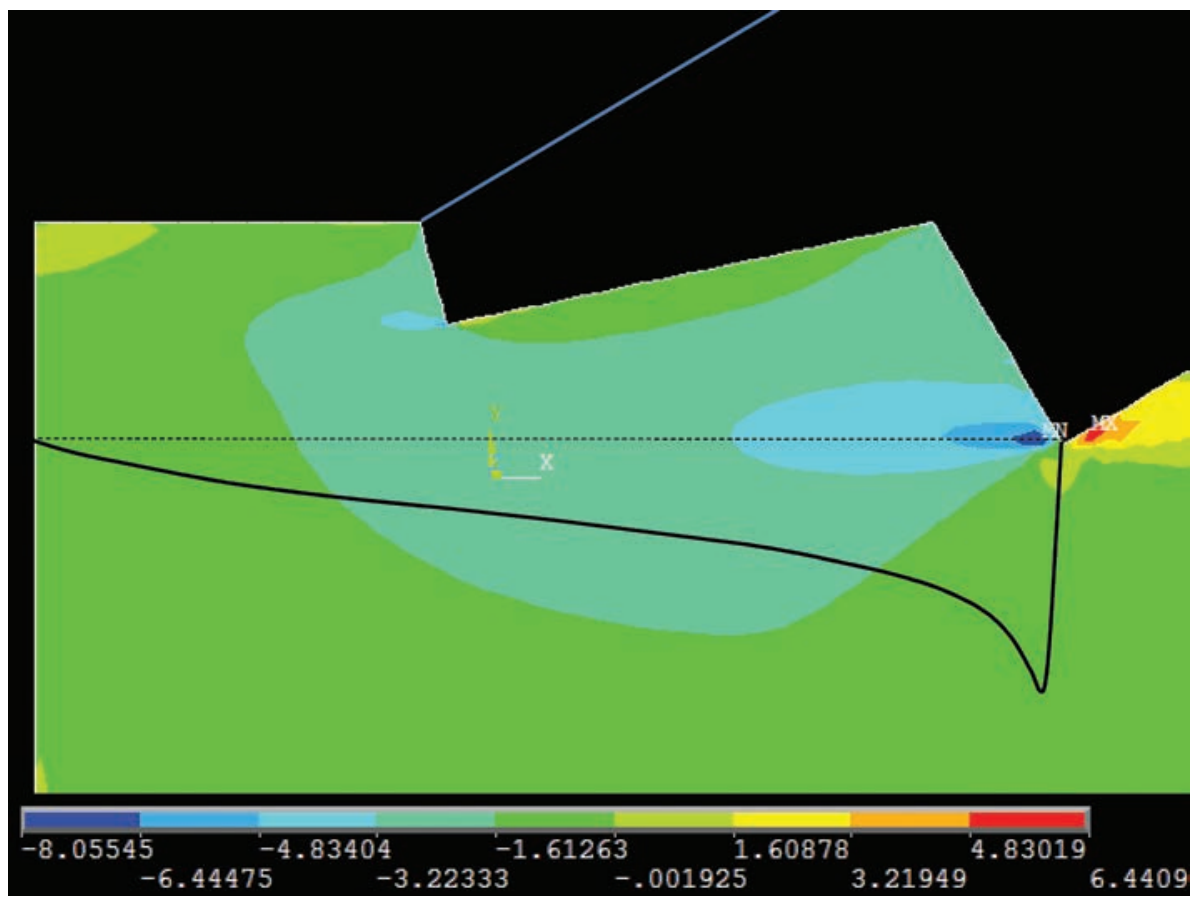

FIGURE 14. Shear stress $\tau_{\mathrm{xy}}(\mathrm{N} / \mathrm{mm} 2)$ and distribution along the crack path for a rafter load of $160 \mathrm{kN}$.

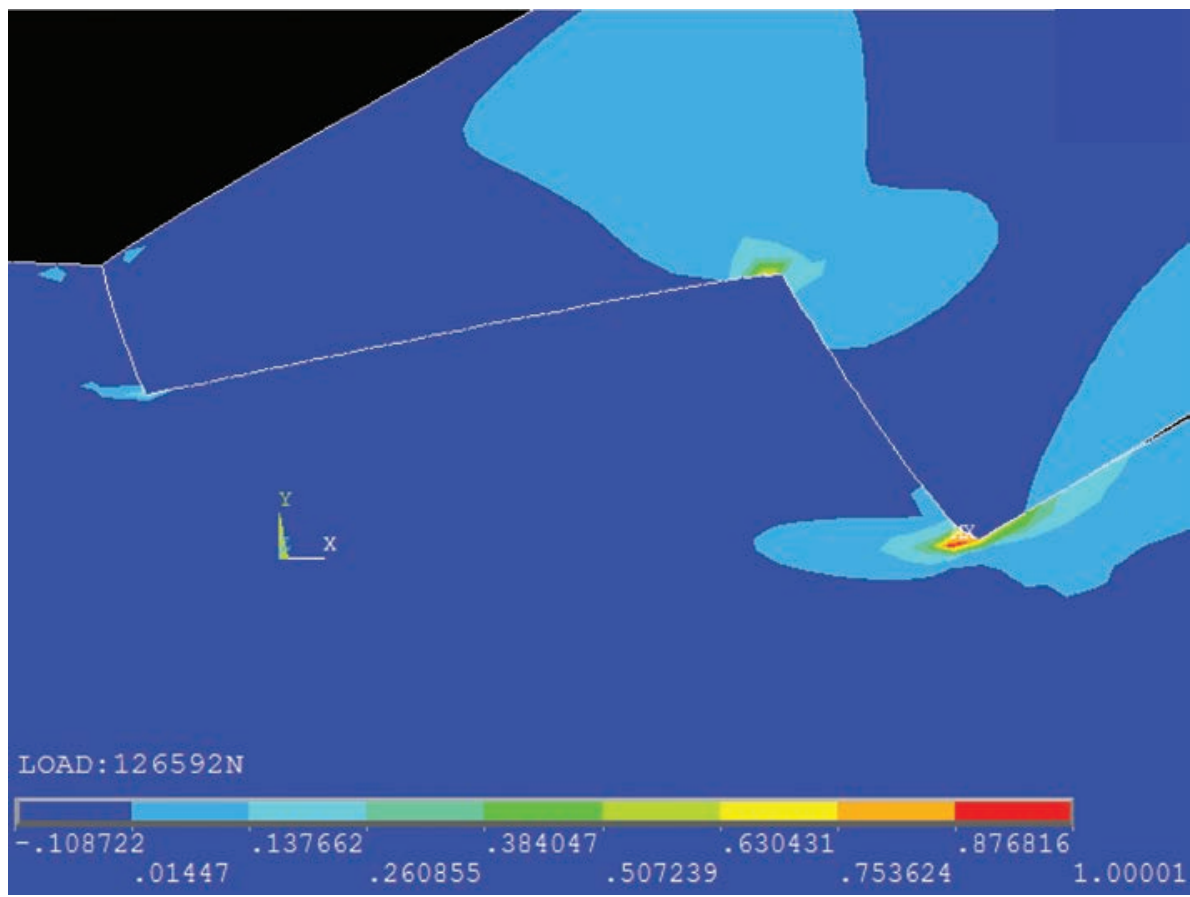

FIGURE 15. Failures rates using the Tsai-Wu criterion.

Thus, it can be checked that the area where the failure originates (failure rate $=1$ ) is the same one at which the high shear stresses concentration was previously observed. Therefore being, this result, coherent with the experimentation and with the origin of the crack.
The failure value obtained with this criterion was $126.592 \mathrm{kN}$ vs. $160 \mathrm{kN}$ experimentally obtained. It implies that the collapse would occur at $79.12 \%$ of the average rafter load reached in the tests. This conservative behaviour is not so pronounced if we take into account the lower value 
obtained in the experimental tests, $134.2 \mathrm{kN}$. This agrees with that observed in other works, where the Tsai-Wu criterion was estimated as conservative $(25,29)$.

\section{CONCLUSIONS}

The test of real size specimens of the double-step joints subjected to constructive loads has allowed to collect records of the strains associated to these loads, as well as to appreciate the way its failure occurs. The main point of the strength of these joints with an angle of $30^{\circ}$ between members, frequently used in large or medium span roofs trusses, is the shearing failure. When the geometrical definition is based on Spanish structural timber standard, the failure is produced by shearing at the lower shear path from the rear notch. Hence, it seems to be reasonable that the shear path is checked only for this plane according to this standard. The oblique compression to the fibre was not critical since failure due to crushing was not detected in any of the two steps. The double-step joint combines the advantages of the single, front notched, step joint and the reverse step joint in order to transmit higher forces. When comparing with these single step joints, significant increases were observed in the experimental failure load.

Small values of strains were appreciated, which did not impede a suitable record of data using strain gauges. After the coupling of the bars at the beginning, an elastic and linear pattern was appreciated until a quasi-brittle failure appeared. A gap at the front notch surface was recommended to ensure the collaboration of the two steps to optimise the load capacity of the joint.

Numerical models using FEM were generated for the pieces tested both with elasticity properties using reported values and with those obtained from the ultrasound study of the specimens tested. These ones could suitably reflect the behaviour observed at the experimental stage. They were graphically and mathematically validated, which will allow studying other geometries and strength classes, among others.

The stress state showed by the FEM models were in agreement with the failure form experimentally observed. The initial geometry of the joint implies that in the transmission of the load to the tie-beam, the rear notch is more loaded. This confirms the calculation of the path affected by the shear stress only from this rear notch when using this geometrical definition. Therefore, the double-step joint allows considering a longer chord shear length with respect to single joints, since the limiting shearing path is the lower one from the rear notch.

The triple strain gauges located at the shear path allowed one to know the concentration of stress, SCF, produced if compared with the theoretical uniform distribution. The FEM model exhibited a distribution of the shear stress resembling a triangular shape with the maximum concentration of stress close to the contact surface. Both, experimental and FEM models provide an SCF greater than 2. Therefore, when the theoretical calculation is conducted, using a reduction coefficient of the shear strength, related to the stresses' distribution, is strongly recommended. The analysis undertaken here pointed out that the $\mathrm{k}_{\mathrm{v}, \mathrm{red}}$ factor would be near the more restrictive values suggested by some authors.

The application of this study to other species, skew angles and geometrical designs could allow extrapolating these results. In that case, general calculation recommendations could be provided since this factor is only considered by some European Standards.

The numerical models included the Tsai-Wu failure criterion. This criterion confirmed the experimental mode of failure and the area where the shear crack began.

\section{ACKNOWLEDGEMENTS}

The Spanish Government supported this work, research project: AGL2012-39368-C03-01, National $\mathrm{R}+\mathrm{D}+\mathrm{I}$ Plan of the Ministry of Science and Innovation. The authors are grateful to Besteiro Timber Factory for the glulam timber supplied.

\section{REFERENCES}

1. Villar, J.R.; Vidal, P.; Fernández, M.S.; Guaita, M. (2016) Genetic algorithm optimisation of heavy timber trusses with dowel joints according to Eurocode 5 . Biosyst Eng. 144, 115-132. https://doi.org/10.1016/j. biosystemseng. 2016.02.011

2. Parisi, M.A.; Piazza, M. (2000) Mechanics of plain and retrofitted traditional timber connections. J. Struct. Eng. 126, 1395-1404. https://doi.org/10.1061/(ASCE) 0733-9445(2000)126:12(1395).

3. Villar, J.R.; Guaita, M.; Vidal, P.; Arriaga, F. (2007) Analysis of the Stress State at the Cogging Joint in Timber Structures. Biosyst Eng. 96, 79-90. https://doi. org/10.1016/j.biosystemseng.2006.09.009.

4. Villar, J.R.; Guaita, M.; Vidal, P.; Argüelles, R. (2008) Numerical simulation of framed joints in sawn-timber roof trusses. Spanish J. Agric. Res. 6, 508-520. https://doi. org/10.5424/sjar/2008064-345.

5. Villar-García, J.R.; Crespo, J.; Moya, M.; Guaita, M. (2018) Experimental and numerical studies of the stress state at the reverse step joint in heavy timber trusses. Mater Struct. 51:17. https://doi.org/10.1617/s11527-018-1144-9.

6. Feio, A.O.; Lourenço, P.B.; Machado, J.S. (2014) Testing and modeling of a traditional timber mortise and tenon joint. Mater Struct. 47, 213-225. https://doi.org/10.1617/ s11527-013-0056-y.

7. Parisi,M.A.; Cordié, C. (2010) Mechanical behaviour of double-step timber joints. Constr. Build. Mater. 24, 1364-1371. https://doi.org/10.1016/j.conbuildmat.2010.01.001.

8. Branco, J.M.; Piazza, M.; Cruz, P.J.S. (2011) Experimental evaluation of different strengthening techniques of traditional timber connections. Eng. Struct. 33, 2259-2270. https://doi.org/10.1016/j.engstruct.2011.04.002.

9. Palma, P.; Cruz, H. (2007) Mechanical behaviour of traditional timber carpentry joints in service conditions-results 
of monotonic tests. Proc. 16th Int. Conf. From Mater. to Struct. - Mech. Behav. Fail. Timber Struct. ICOMOS Int. Wood Comm.

10. Palma, P.; Ferreira, J.; Cruz, H. (2010) Monotonic tests of structural carpentry joints. World Conf. Timber Eng. (2010).

11. Verbist, M.; Branco, J.M.; Poletti, E.; Descamps, T; Lourenço, PB. (2017) Single Step Joint: overview of European standardized approaches and experimentations. Mater Struct. 50, 161. https://dx.doi.org/10.1617/ s11527-017-1028-4.

12. CEN EN 1995-1-1:2016. Eurocode 5: Design of timber structures - Part. 1.1 General. Common rules and rules for buildings.

13. CTE-DB-SE-M 2009 Spanish Technical Building Code, Structural Security, Timber Structures.

14. NEN NEN-EN 1995-1-1+C1+A1:2011/NB:2013nl. National Annex to NEN-EN 1995-1-1+C1+A1 Eurocode 5: Design of timber structures - Part 1-1: General Common rules and rules for buildings.

15. SIA 265:2012. Timber Structures. Swiss Society of Engineers And Architects.

16. Argüelles Álvarez, R.; Arriaga, F.; Esteban, M.; Íñiguez, G.; Argüelles Bustillo, R. (2015) Estructuras de Madera. Uniones (Timber Structures. Joints), AITIM. Asociación de Investigación Técnica de las Industrias de la Madera y Corcho. Madrid

17. Aira, J.R.; Íñiguez-González, G.; Guaita, M.; Arriaga, F. (2016) Load carrying capacity of halved and tabled tenoned timber scarf joint. Mater Struct. 49, 5343-5355. https://doi.org/10.1617/s11527-016-0864-y.

18. CEN EN 14080:2013. Timber structures. Glued laminated timber and glued solid timber. Requirements

19. Argüelles Álvarez, R. (1992) Fundamentos de elasticidad y su programación por elementos finitos, (Fundamentals of elasticity and finite element programming), Bellisco. Madrid, (1992)

20. Ortiz Berrocal, L. (2007) Resistencia de Materiales (Strength of Materials), 3rd ed, MCGRAW-HILL, Madrid.

21. CEN EN 408:2011+A1:2012. Timber structures - Structural timber and glued laminated timber - Determination of some physical and mechanical properties.

22. Koch, H.; Eisenhut, L.; Seim, W. (2013) Multi-mode failure of form-fitting timber connections - Experimental and numerical studies on the tapered tenon joint. Eng. Struct. 48, 727-738. https://doi.org/10.1016/j.engstruct. 2012.12.002.

23. Baño, V.; Argüelles-Bustillo, R.; Regueira, R.; Guaita, M. (2012) Determination of the stress-strain curve in specimens of Scots pine for numerical simulation of defect free beams. Mater. Constr. 62 [306], 269-284. https://doi. org/10.3989/mc.2012.64110.

24. Sangree, R.H.; Schafer, B.W. (2009) Experimental and numerical analysis of a halved and tabled traditional timber scarf joint. Constr. Build. Mater. 23, 615-624. https:// doi.org/10.1016/j.conbuildmat.2008.01.015.

25. Soilán, A.; Arriaga, F.; Baño, V.; Crespo, J.; Guaita, M. (2011) Analysis of the behaviour of the dovetail connection by numerical simulation with the finite element method. In: Joao Negrao y Alfredo G. Dias, editor. Proceeding 1er Ibero-Latin Am. Congr. wood Constr. CIMAD 11., Coimbra, Portugal.

26. Aira, J.R (2013) Análisis experimental y por el método de los elementos finitos del estado de tensiones en uniones carpinteras de empalme de llave. PhD thesis, Universidad Politécnica de Madrid.

27. ANSYS Inc. ANSYS $®$ (2012) Academic Research, Release 14.0: Help System: ANSYS Mechanical APDL theory reference.

28. Tsai, S.W.; Wu, E.M. (1971) A General Theory of Strength for Anisotropic Materials. J. Compos. Mater. 5, 58-80. https://doi.org/10.1177/002199837100500106.

29. Guindos, P (2011) Three Dimensional Finite Element Models to Simulate the Behaviour of Wood with Presence of Knots, Appling The Flow-Grain Analogy and
Validation with Close Range Photogrammetry. PhD thesis, University of Santiago de Compostela.

30. Goldenblat, I.I.; Kopnov, V.A. (1965) Strength of glass reinforced plastics in the complex stress state. Polym. Mech. 1, 54-59. https://doi.org/10.1007/BF00860685.

31. Cabrero, J.M.; Gebremedhin, K.G.; Elorza, J. (2009) Evaluation of Failure Criteria in Wood Members. ASABE Annu. Int. Meet., American Society of Agricultural and Biological Engineers. ASABE. Reno, Nevada, EE.UU. (2009) https://doi.org/10.13031/2013.27030.

32. Eberhardsteiner, J. (2002) Mechanisches Verhalten von Fichtenholz. Vienna: Springer Vienna. https://doi. org/10.1007/978-3-7091-6111-1.

33. Schmidt, J.; Kaliske, M. (2008) Models for numerical failure analysis of wooden structures. Eng. Struct. 31, 571-579. https://doi.org/10.1016/j.engstruct.2008.11.001.

34. Dahl, K.B. (2009) Mechanical properties of clear wood from Norway spruce. $\mathrm{PhD}$ thesis, Norwegian University of Science and Technology.

35. Resch, E.; Schmidt, J.; Gereke, T.; Kaliske, M. (2004) GröBe und Einfluss der Streuung der elastischen Eigenschaften von Fichtenholz. (Size and influence of the dispersion of the elastic properties of spruce). LACER. 9, 417-432.

36. Bucur, V. (2006) Acoustics of wood. 2nd ed., SpringerVerlag Berlin Heidelberg, (2006) https://doi.org/10.1007/ 3-540-30594-7.

37. Majano-Majano, A.; Fernández-Cabo, J.L.; Hoheisel, S.; Klein, M. (2012) A Test Method for Characterizing Clear Wood Using a Single Specimen. Exp. Mech. 52, 1079-1096. https://doi.org/10.1007/s11340-011-9560-6.

38. Vázquez, C.; Gonçalves, R.; Bertoldo, C.; Baño, V.; Vega, A.; Crespo, J. (2015) Determination of the mechanical properties of Castanea sativa Mill. using ultrasonic wave propagation and comparison with static compression and bending methods. Wood Sci. Technol. 49, 607-622. https:// doi.org/10.1007/s00226-015-0719-7.

39. Gonçalves, R.; Trinca, A.J.; Cerri, D.G.P. (2011) Comparison of elastic constants of wood determined by ultrasonic wave propagation and static compression testing. Wood Fiber Sci. 43, 64-75.

40. Conde-García, M.; Fernández-Golfín Seco, J.I.; Hermoso Prieto, E. (2007) Improving the prediction of strength and rigidity of structural timber by combining ultrasound techniques with visual grading parameters. Mater. Constr. 57 [288], 49-59. https://doi.org/10.3989/ mc.2007.v57.i288.64.

41. UNE 56543, Características físico-mecánicas de la madera. Determinación del esfuerzo cortante (PhysicalMechanical Properties of Wood. Determination of the Shear Strength).

42. ASTM D143:14 Standard test methods for small clear specimens of timber. ASTM International, West Conshohocken, PA

43. Aira, J.R.; Arriaga, F.; Íñiguez-González, G.; Crespo, J. (2014) Static and kinetic friction coefficients of Scots pine (Pinus sylvestris L.), parallel and perpendicular to grain direction, Mater. Constr. 64 [315], e030. https://doi. org $/ 10.3989 / \mathrm{mc} .2014 .03913$.

44. Crespo, J.; Regueira, R.; Soilán, A.; Díez, M.R.; Guaita, M. (2011) Methodology to determine the coefficients of both static and dynamic friction apply to different species of wood. In: Joao Negrao y Alfredo G. Dias, editor. Proceeding 1er Ibero-Latin Am. Congr. wood Constr. CIMAD 11, Coimbra, Portugal.

45. Smith, I.; Landis, E.; Gong, M. (2003) Fracture and Fatigue in Wood, Wiley, Chichester, (2003).

46. DIN EN 1995-1-1/NA:2013. Nationaler Anhang. National festgelegte parameter. Eurocode 5: Bemessung und konstruktion von reglen für den hochbau. (National Annex. Nationally determined parameters. Eurocode 5: Design of timber structures Common rules and rules for buildings).

47. Bocquet, J.F. (2015) Traditional structural assemblies in the future regulatory context. Eurocode 5: design and calculation of wooden structures. Formation ENSTIB. 
16 •J. R. Villar-García et al.

National School of Wood Science and Timber Engineering University of Lorraine, Nancy, Lorraine, (2015).

48. Aira, J.R.; Arriaga, F.; İñiguez-González, G. (2014) Determination of the elastic constants of Scots pine (Pinus sylvestris L.) wood by means of compression tests. Biosyst Eng. 126, 12-22. https://doi.org/10.1016/j. biosystemseng.2014.07.008.
49. Colling, F. (2008) Holzbau, Vieweg+Teubner, Wiesbaden, (2008). doi:10.1007/978-3-8348-9551-6.

50. Aira, J.R.; Descamps, T.; Van Parys, L.; Léoskool, L. (2015) Study of stress distribution and stress concentration factor in notched wood pieces with cohesive surfaces. Eur J Wood Wood Prod. 73, 325-334. https://doi.org/10.1007/ s00107-015-0891-3. 